\title{
Cardiac involvement (Wolff-Parkinson-White syndrome) in tuberous sclerosis
}

\author{
Olajide Ijaola, L.C. Festus-Abibo' ${ }^{1}$, Olu Lawani ${ }^{1}$ and Sonny F. Kuku ${ }^{1}$ \\ Cardiology Department, King's College Hospital, London SE5 9RS, UK and ${ }^{1}$ The EKO Hospital, Lagos, \\ Nigeria
}

\begin{abstract}
Summary: A surface electrocardiogram showing type B Wolff-Parkinson-White syndrome pattern was part of the cardiac findings in a female of $\mathbf{2 4}$ with florid features of tuberous sclerosis. She had cardiomegaly but no intracardiac tumour was demonstrated. Wolf - Parkinson-White syndrome, though rare, has previously been described in association with tuberous sclerosis in children but not before in adults.
\end{abstract}

\section{Introduction}

Tuberous sclerosis is a congenital autosomal dominant inherited disease with incomplete penetrance and variable expressivity. About $60 \%$ of cases occur by new mutation. Most patients appear normal at birth but later develop variable clinical features of the disease such as facial adenoma sebaceum, other skin tumours, subungual fibromas, and various affectations of the brain, eyes, lungs, heart, liver, kidneys, adrenals, pancreas and bones. ${ }^{1}$ Rhabdomyoma is the cardinal cardiac lesion found. This may produce symptoms by valvular or intracardiac obstructions or congestive cardiac failure because of infiltration by non-contractile tumour tissues. Various types of dysrrhythmias have previously been reported including atrial and ventricular tachycardia, junctional ectopic beats and various degrees of atrioventricular or His bundle branch blocks. ${ }^{2}$ Wolff-Parkinson-White syndrome is rare but has been described in children with tuberous sclerosis. ${ }^{3}$ We present a case of tuberous sclerosis in a 24 year old female in whom the electrocardiogram showed the pattern of type B Wolff-Parkinson-White syndrome.

\section{Case report}

The patient, aged 24 , presented with dragging abdominal mass, palpitations and typical cutaneous features of tuberous sclerosis. There was no history of frank haematuria. Her illness dated back to infancy when facial tumours and skin nodules

Correspondence: O. Ijaola, M.B., F.M.C.P. Accepted: 28 July 1993

were first noticed. She subsequently developed subungual fibromas which tended to recur after repeated ablations. Two months before presenta-

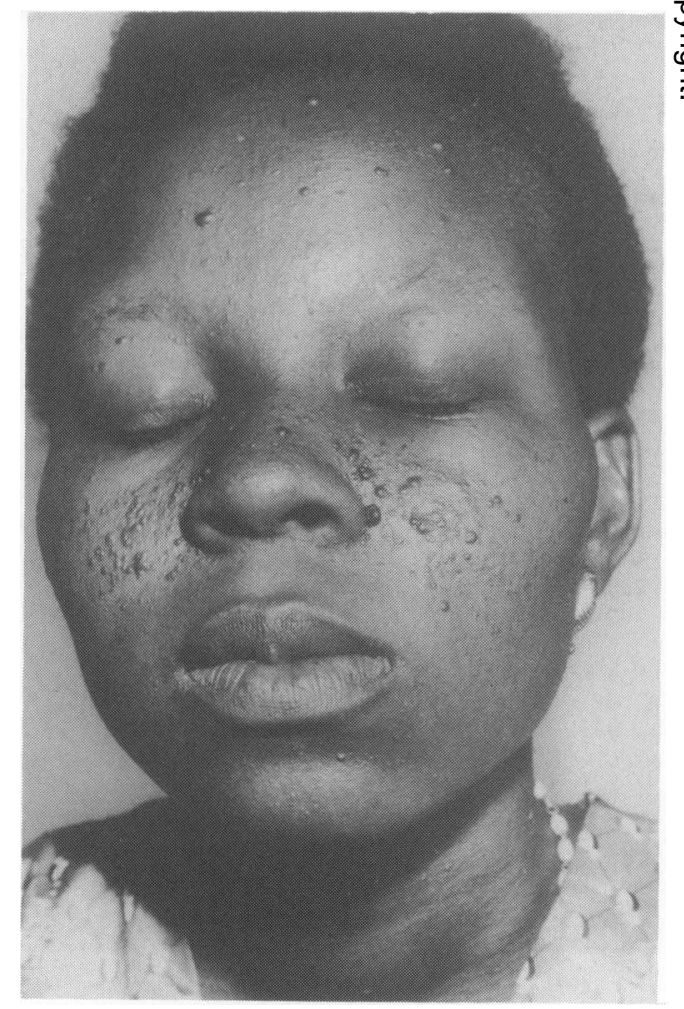

Figure 1 Facial nodular rashes (adenoma sebaceum) of tuberous sclerosis in a 24 year old patient. 
tion she experienced progressive weakness, exertional shortness of breath and palpitations. There was no cough or pedal oedema. About the time of presentation, she became profoundly paranoid, believing that she was bewitched by her father and sister, who is also psychotic. She subsequently became psychotic herself, requiring institutionalized care and treatment with chlorpromazine and benzhexol. There was no history of any other prior drug ingestion.

Her mother died at age 30 years. Her twin sister died in infancy. An older sister and a brother are alive. The sister has schizophrenic psychosis but no other evidence of tuberous sclerosis. The brother is normal. All five siblings (three girls and two boys) by a stepmother are normal. Clinical and ultrasound examinations of all members of the family, including her psychotic sister, did not reveal any lesion of tuberous sclerosis except the father who has few facial nodules but surprisingly gross scrotal skin tumours. Hypomelanotic spots were, however, not elicited either in him or any other member of the family. None of them gave a history of palpitations and their electrocardiograms were normal, including that of the psychotic sister.

On examination our patient had florid skin lesions of tuberous sclerosis including widespread hypomelanotic macules, adenoma sebaceum, and nodular skin and nail tumours (Figures 1 and 2).
She was not in heart failure. She was in sinus rhythm but had frequent ventricular ectopic beats. The arterial blood pressure was normal. There was moderate cardiomegaly but no sustained left ventricular heave. The heart sounds were normal. Her lungs were clear to auscultation. Bilateral renal cystic masses were readily palpable. The liver and spleen were not palpably enlarged. She was of average intelligence but lacked insight into her disturbed mind. No focal neurologic sign was elicited.

Electrocardiography (Figure 3) showed sinus rhythm but frequent ventricular ectopics. The electrocardiogram was consistently that of type B Wolff-Parkinson-White syndrome with PR interval of 80 milliseconds, widened QRS duration of 12 milliseconds, delta waves which were positive in lead 1 and predominantly negative QRS in V1. No episode of tachycardia or atrial fibrillation was, however, elicited. Her echocardiogram showed enlarged left ventricular end diastolic dimensions of $6.6 \mathrm{~cm}$. No intracardiac mass was seen and the valves were normal. Skull $\mathrm{X}$-rays and electroencephalogram were normal. Histology of the subungual fibroma was consistent with tuberous sclerosis.

Abdominal ultrasound revealed grossly enlarged kidneys bilaterally with cystic degenerations. There were other discrete hyperechoeic tissues within

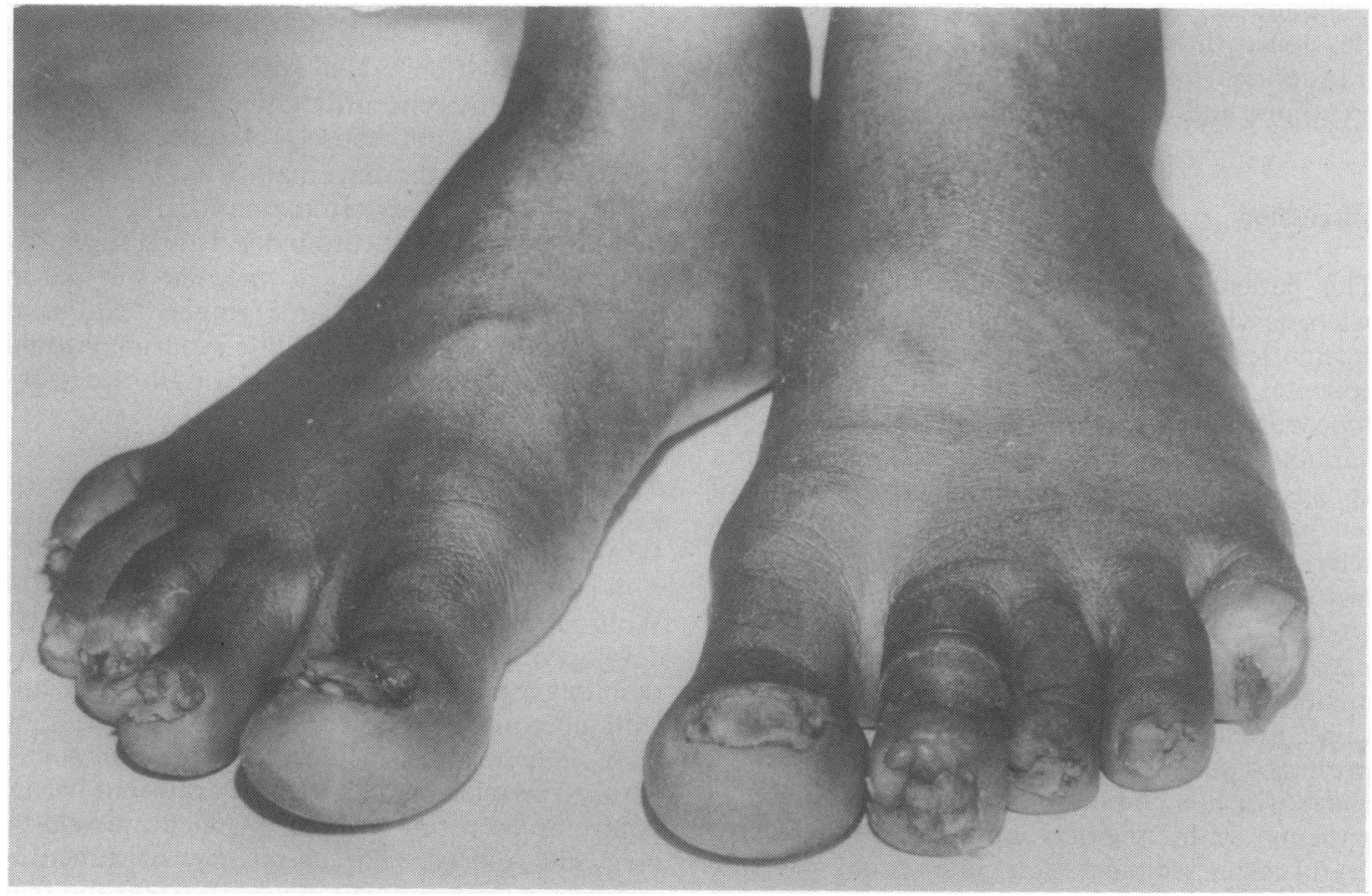

Figure 2 Subungual fibromas in the same patient. 

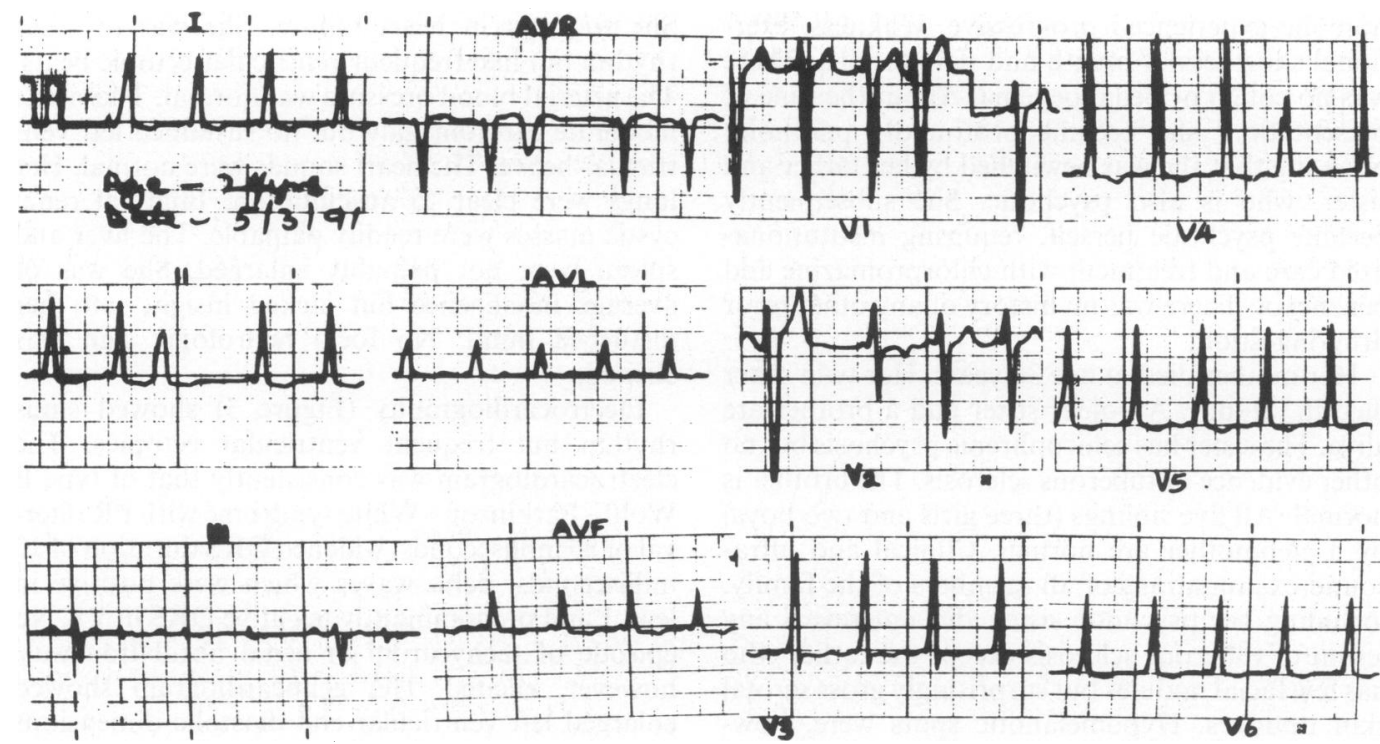

Figure 3 Electrocardiograph of the same patient exhibiting the pattern of type B Wolff-Parkinson-White syndrome.

both kidneys consistent with angiomyolipoma. Her haematocrit was $27 \%$ and the erythrocyte sedimentation rate was $114 \mathrm{~mm} /$ hour. Her haemoglobin genotype was AA. Urinalysis showed significant pyuria of 20 cells per high-power field and albuminuria $(1+)$. The liver enzymes were mildly elevated with both alanine and aspartate aminotransferases of 96 units, respectively. Serum creatinine and electrolytes were normal.

\section{Discussion}

This patient illustrates a florid case of tuberous sclerosis with facial, skin, nail, cardiac, kidney and splenic lesions. ${ }^{1}$ She was also psychotic but not epileptic, two of the common manifestations of tuberous sclerosis. ${ }^{4}$ Tuberous sclerosis has highly variable expressivity and psychosis without epilepsy is a recognized sole manifestation. ${ }^{5}$ Out of ten patients in whom the diagnosis of tuberous sclerosis was eventually made, Rakoff ${ }^{4}$ elicited a history of schizophrenic psychosis in two, one of whom had no epilepsy. The renal ultrasound in this patient was consistent with a mixture of both angiomyolipoma and cystic degeneration. The cause of her anaemia was not definite but was presumed to be due, at least in part, to haemorrhage which is common but often intermittent in patients with angiomyolipoma. Her elevated erythrocyte sedimentation rate could also be related to the anaemia per se as no other cause was found.
Partial expression of tuberous sclerosis may also manifest solely with cardiac rhabdomyoma. Rhabdomyoma occurs in about $30-40 \%$ of patients with tuberous sclerosis in childhood. ${ }^{6}$ The tumouro is rare in adults suggesting that it may regress? spontaneously. ${ }^{7}$ When associated with tuberous sclerosis, they are usually intramural, unlike those found in isolation. ${ }^{8}$ The absence of detectable cardiac mass by echocardiography in this patient, therefore, does not entirely exclude a previous occurrence of rhabdomyomata which may be in various stages of regression, considering her age. Indeed, the finding of cardiomegaly might suggest definite cardiac involvement since she was not in heart failure. The electrocardiographic features of type B Wolff-Parkinson-White syndrome would tend to suggest the presence of a right accessory atrio-ventricular bypass tract.

Wolff-Parkinson-White syndrome has been described in association with tuberous sclerosis with $^{3,6}$ or without ${ }^{6,9}$ cardiac rhabdomyoma. Jayakar et al. ${ }^{3}$ described two infants who presented with supraventricular tachycardia and features of Wolff-Parkinson-White syndrome and who later developed tuberous sclerosis, one with cardiac rhabdomyoma. They were among seven patients with tuberous sclerosis seen over a 9-year period by these authors who concluded that the probability of tuberous sclerosis and Wolff-Parkinson-White syndrome occurring together by chance would be very low indeed. The frequency of tuberous sclerosis in their population was $1: 20,000$ and that of supraventricular tachycardia was 1:25,000, 
while only $23-25 \%$ of their children with supraventricular tachycardia had Wolff-ParkinsonWhite syndrome.

The precise mechanism responsible for the occurrence of Wolff-Parkinson-White syndrome in tuberous sclerosis is not completely certain. Two mechanisms are plausible. Some cells in the cardiac rhabdomyoma in tuberous sclerosis resemble normal Purkinje cells structurally. ${ }^{2,10}$ These Purkinjelike cells have therefore been thought to be capable

\section{References}

1. Gomez, M.R. Criteria for diagnosis. In: Gomez, M.R. (ed.) Tuberous Sclerosis, 2nd edn. Raven Press, New York, 1988, pp. 9-19.

2. Mair, D.D., Edwards, E.D. \& Seward, J.B. Cardiac manifestations. In: Gomez, M.R. (ed.) Tuberous Sclerosis, 2nd edn. Raven Press, New York, 1988, pp. 147-158.

3. Jayakar, P.B., Stanwick, R.S. \& Seshia, S.S. Tuberous sclerosis and Wolff-Parkinson-White syndrome. J Paediatr 1986, 108: $259-260$.

4. Rakoff, J. Tuberous sclerosis in the aetiology of the so-called idiopathic epilepsies and psychosis. South African Med J 1981, 60: 574-578.

5. Herkert, E.H., Wald, A. \& Romeo, O. Tuberous sclerosis and schizophrenia. Diseases Nervous System 1972, 33: 439-445. of functioning as an anomalous conducting tract for pre-excitation syndrome. ${ }^{2,3}$ However, this may not explain the cases in which the tumour does not occur or has regressed. On the other hand it is possible that pre-excitation syndrome may also result from the splitting up of the conduction tract by infiltrating tuberous sclerosis tissues, creating accessory pathways in some patients. It may be of interest to do electrophysiological studies in a cohort of patients with tuberous sclerosis.

6. Van der Hauwaert, L.G. Cardiac tumours in infancy and childhood. Br Heart J 1971, 33: 125-132.

7. Smith, H.C., Watson, G.H., Patel, R.G. \& Super, M. Cardiac rhabdomyomata in tuberous sclerosis: their course and diagnostic value. Arch Dis Child 1989, 64: 196-200.

8. Fenoglio, J.J., Jr, McAllister, H.A., Jr \& Ferrans, V.I. Cardiac rhabdomyomas: a clinicopathologic and electron microscopic study. Am J Cardiol 1976, 38: 341-251.

9. Swiderski, J., Lees, M.H. \& Nados, A.S. The Wolff-Parkinson-White syndrome in infancy and childhood. Br Heart J 1962, 24: 561.

10. Crome, L. The structural features of epiloia, with special reference to endocardial fibroelastosis. J Clin Pathol 1954, 7: 137. 